Article

\title{
Mathematical Modeling Projects Oriented towards Social Impact as Generators of Learning Opportunities: A Case Study
}

\author{
Lluís Albarracín *(D) and Núria Gorgorió \\ Departament de Didàctica de les Ciències Experimentals i la Matemàtica, Universitat Autònoma de Barcelona, \\ 08193 Bellaterra (Barcelona), Spain; nuria.gorgorio@uab.cat \\ * Correspondence: lluis.albarracin@uab.cat
}

Received: 23 October 2020; Accepted: 12 November 2020; Published: 15 November 2020

check for updates

\begin{abstract}
This paper presents a case study carried out at an elementary school that led to a characterization of mathematical modeling projects aimed at generating social impact. It shows their potential as generators of mathematical learning opportunities. In the school project, upper-grade students (sixth grade, 11-year-olds) studied the way in which the rest of the students at the institution traveled from their homes to school. Its purpose was to identify risk points from the standpoint of road safety and to develop a set of recommendations so that all the children could walk safely to school. In our study, we identified, on the one hand, the mathematical learning opportunities that emerged during the development of the project and, on the other, the mathematical models created by the students. We discuss the impact of the project on the different groups in the school community (other students, parents, and teachers). We conclude with a characterization of the mathematical modeling projects oriented towards social impact and affirm that they can be generators of mathematical learning opportunities.
\end{abstract}

Keywords: mathematical modeling; modeling projects; elementary school; learning opportunities

\section{Introduction}

Mathematical modeling in the classroom encourages students to develop mathematical knowledge through the study of real-life situations, taking advantage of the link between reality and mathematical concepts and procedures (Blum [1]; Doerr and English [2]). Our participation, as researchers in various school projects in which the mathematical analysis of reality is a central part of the work, inspired us to propose the concept of the mathematical modeling project oriented towards social impact (MMPOSI). By way of an initial approach to the concept, we established that the elements defining an MMPOSI are structured around two key ideas: the role of mathematical modeling and its social component. In this article, we exemplify the concept of MMPOSI through a case study developed from a naturalistic perspective at an elementary school. Thus, the case studied allowed us to characterize MMPOSIs and exemplify their potential by showing how they can generate mathematics learning opportunities in elementary school (Cai et al. [3]; Cobb and Whitenack [4]). Given that this research was designed as a case study with an instrumental descriptive character (Merriam [5]; Stake [6-8]), we leave the characterization and discussion of the concept of MMPOSI to the end of the article.

The school where this case study was developed is in the center of Sabadell (Spain), a city with 200,000 inhabitants. The streets around the school are narrow and were laid out prior to motorized vehicles. They are now used by both road traffic and pedestrians. In 2017, an accident occurred in which one of the students was run over by a vehicle while returning home from school. This accident had a huge impact on the school community. New needs emerged both for students and their families, 
as well as for teachers. Among the various actions taken, the school management team, in coordination with the parents' association, requested the assistance of the first author of this paper to carry out a project in which the pupils would study the difficulties they encountered in their everyday journeys on foot to and from the school. This request provided the basis of the school project "Let's get to school safely", in which upper-grade students (11-year-olds) were given the task of documenting the routes taken by the rest of the students to get to school, then analyzing the findings to identify the pedestrian danger points. The final goal of the project was to generate a set of indications that would ensure that the students could safely walk to the school through the city streets.

The text of this article is organized according to the structure that often appears in reports of instrumental descriptive case studies. In Sections 2 and 3, the conceptual framework of the study is introduced. In the second section, we explain the interpretation of the mathematical modeling that we apply when establishing the definition of MMPOSI and, in the third, the meaning that we give mathematical learning opportunities to justify our methodology. The empirical study is presented in a block consisting of Sections 4 and 5. The fourth section justifies and details the choice of a case study as the research design, and the fifth explains the chronological progress of the project Let's get to school safely. The results, which are essentially descriptive given the nature of the study, are the themes that emerge from the study and are presented in Sections 6 and 7. The sixth section describes the mathematical learning opportunities that emerged during the course of the project and, in the seventh, the models generated by the students. Sections 8 and 9 bring the article to a close. In the eighth section, we discuss the learning opportunities and models identified, and in the ninth, we conclude the article by setting out the basic characteristics of MMPOSIs.

\section{Modeling in Mathematics Education}

\subsection{Background}

Mathematical modeling as a research topic in the field of mathematics education began with the work of Pollak [9], who discussed the relationship between the applications of mathematics and the teaching/learning processes. Subsequently, the same Pollak [10] presented a first theoretical framework, which interpreted modeling processes by differentiating between the mathematical domain and the rest of the world. This separation necessarily leads us to the process of mathematizing a phenomenon, moving from reality to the mathematical domain, and to the interpretation within the real context of the models generated in the mathematical domain, as a form of validation.

Following Blum [1], mathematical modeling was established as a research topic of interest in mathematics education, aimed at setting up classroom activities that bring to light the close relationship between mathematics and the world around us. A great deal of research on educational mathematical modeling has been carried out since then, and it has diversified remarkably, in terms of both the goals and the approaches (Abasian, Safi, Bush, and Bostic [11]; Blomhøj [12]; Kaiser and Sriraman [13]). Thus, from the perspective of the mathematization of the environment and mathematical modeling, a clear need has been identified at an international level to link up students' mathematical knowledge with reality (Vorhölter, Kaiser, and Borromeo Ferri [14]).

Recently, Blum [15] reaffirmed that the teaching of applications and modeling has a twofold function: on the one hand, the knowledge of mathematics and its applications is vital to the real world and its advancement, principally with regard to solving real problems and developing complex projects; and on the other hand, the real world and the way it integrates mathematical knowledge are extremely important as a vehicle for giving meaning to the learning of mathematical concepts and, in general, mathematics as a discipline.

The theoretical advances made in the didactic use of modeling are well known. However, their presence has not yet been felt in the majority of classrooms. There are various reasons why the use of mathematical modeling has not increased in elementary and secondary education classrooms. For example, institutional constraints have been identified that make it difficult to fit modeling activities 
into the normal functioning of educational centers (Barquero, Bosch, and Romo [16]). It has also been observed that teachers' attitudes and their training are key to the regular use of modeling activities (Blum and Leiß [17]; Schmidt [18]). Indeed, many mathematics teachers do not think modeling is an essential component of learning mathematics, and they also question their own mathematical modeling skills. Given that students may come up with many different solutions and it is not easy to identify the focus of the activity in these tasks, teachers regard the implementation of mathematical modeling tasks as rather complex (Ng [19]; Winter and Venkat [20]). These difficulties are possibly more marked among elementary school teachers, since their training is less grounded in mathematics.

\subsection{Models and Modeling Activity}

Problem solving is a key part of mathematics education (Lester [21]; Schoenfeld [22]). In this paper, we argue that contextualized problem solving activities can be interpreted as mathematical modeling activities, given the type of mathematical constructions that students create to solve them. Our approach is situated in that area of research that explores how students solve mathematical problems, situated in real contexts, when there are no defined heuristics. These problems promote metacognition and help to familiarize students with the methods of applied mathematics (Verschaffel [23]). From this perspective, the fundamentals of modeling are aligned with the principles of project-based learning, while promoting active learning (Krajcik and Blumenfeld [24]) in meaningful contexts that students can relate to their prior knowledge (Blumenfeld et al. [25]), with the focus on the development of mathematical activities and concepts. Thus, we consider a class task to be a modeling activity when students generate or use mathematical models to describe or analyze real phenomena. In this paper, we adopt the definition of a mathematical model proposed by Lesh and Harel [26]:

"Models are conceptual systems that generally tend to be expressed using a variety of interacting representational media, which may involve written symbols, spoken language, computer-based graphics, paper-based diagrams or graphs, or experience-based metaphors. Their purposes are to construct, describe or explain other system(s).

Models include both: (a) a conceptual system for describing or explaining the relevant mathematical objects, relations, actions, patterns, and regularities that are attributed to the problem-solving situation; and (b) accompanying procedures for generating useful constructions, manipulations, or predictions for achieving clearly recognized goals." (p. 159)

This definition makes it clear that some of the concepts and procedures that make up a model are mathematical. However, the constructed models may also contain non-formal aspects that allow an intuitive description of the reality under study, such as graphic representations or the use of metaphors. Modeling is a process of solving a real problem in which mathematical concepts, methods, and results are involved (Blum and Niss [27]). To this end, the objects, data, and relationships occurring in reality are transferred to the world of mathematics (horizontal mathematization), thereby obtaining a mathematical model. Mathematical methods are then applied to this model to reach a mathematical solution (vertical mathematization), which must be interpreted and validated in the real world where the problem is framed, resulting in a real solution (again, horizontal mathematization).

It is generally agreed in the world of mathematics education that modeling processes are of a cyclical nature (Blum and Leiß [17]; Carreira, Amado, and Lecoq [28]; Doerr and English [2]; Galbraith and Stillman [29]; Greefrath [30]; Kaiser and Stender [31]). During a modeling process, students try to solve a problem by going through different stages in which they move from reality to the mathematical domain, each time re-evaluating the phenomenon under study. The entire process is repeated in different cycles, with the students improving the models and solutions found for the problem they are working on, adapting the models to the requirements of the problem statement (Blum and Borromeo Ferri [32]). Finally, they have to communicate the result of this process. To successfully find their way through these stages, students have to draw on a series of competences that include aspects related to metacognition, motivation, and their own ideas about the nature of mathematics (Maaß [33]). 
From the theoretical perspective of models and modeling $(\mathrm{M} \& \mathrm{M})$ and from a model-eliciting point of view, students are understood to perform multiple cycles of interpretation, descriptions, conjectures, explanations, and justifications that are redefined and reconstructed iteratively as they interact with other students (Doerr and English [2]). Model building involves quantifying, dimensioning, coordinating, categorizing, algebratizing, and systematizing relevant objects, relationships, actions, patterns, and regularities (Mousoulides, Sriraman, and Christou [34]). The M\&M perspective also considers data-modeling problems that focus on organizing and representing data, building patterns, and searching for relationships (Lesh, Amit, and Schorr [35]), as well as involving students in statistical reasoning such as decision-making, inference, and prediction.

The problems posed to students in the framework of M\&M, contextualized in the real world and with characteristics and demands that make them modeling activities, are called "model-eliciting activities" (MEAs) (Doerr and English [2]). The M\&M approach is integrated into problem solving because it considers that an MEA in itself constitutes the process of modeling and obtaining a model. Thus, the problem statement must allow the students to establish adequate criteria that help to decide which solution is the most appropriate among a set of different alternatives. It should also enable the students to judge for themselves whether the answers need improving, refining, or amplifying for a specific purpose. During an MEA, students are asked to work in small groups (Clohessy and Johnson [36]; Zawojewski, Lesh, and English [37]) and are confronted with a problematic situation that is significant and relevant to them, for which they must create, expand, and perfect their own mathematical constructions.

In MEAs, students are encouraged to generate products that go beyond providing brief answers to artificially restricted questions about pre-mathematized situations. It is a question of enabling the creation of models by the students on the basis of their previous knowledge, both mathematical and about the real world. Students' work during a modeling activity should result in productions that are shareable and re-usable in similar situations (Lesh and Lehrer [38]). Depending on the project needs, students may generate models to provide decision-making tools (Mousoulides, Sriraman, and Christou [34]). Students develop these tools from models that fulfill a functional or operational role. This includes drawing up specific action plans to deal with problematic situations and designing the assessment instruments needed to distinguish different scenarios in complex situations where it is necessary to use specific mathematical models.

\section{Mathematics Learning Opportunities}

There is a wide and continuous spectrum of situations in which learning opportunities have been studied. On the one hand, there are large-scale studies that measure the acquisition of learning. At the opposite extreme, there are micro-studies that address the achievement of specific learning goals, usually in classroom activities. In large-scale studies in general, the goal is to arrive at an interpretation of learning outcomes measured globally through performance tests, either in international comparative studies or accountability studies, or to explain why certain groups (minorities, students with specific needs (Kurz [39]), etc.) do not perform at the same level as the population taken overall. From this perspective, learning opportunities are defined in relation to the the measured contents of the curriculum, the educational level, and the learning conditions. In any case, in this field, the interest is in learning as a product, as a result of certain conditions that include learning opportunities. It is important to note that, under this interpretation, the opportunity is not necessarily thought to imply learning. In fact, Törnroos [40] pointed out that having the opportunity to learn is a necessary prerequisite for learning, but a learning opportunity does not guarantee that students will actually learn. In general, the studies related to learning opportunities try to explain the lack of learning as caused by a lack of opportunities. However, Floden [41] pointed out that other factors influence learning outcomes, including the quality of the teaching and the students' abilities.

At the level of what happens in the classroom, when the term mathematical learning opportunity is discussed, it is initially linked to the analysis of classroom interactions where mathematical knowledge 
is constructed. Cobb and Whitenack [4] argued that mathematics learning is a process of conceptual self-organization and enculturation. From this perspective, a mathematical learning opportunity is a situation in which students have the opportunity to reorganize their conceptual structures and approaches when solving problems or, in general, when dealing with a new mathematical activity. Therefore, it is a concept closely linked to the content being learned, the learning process, and the characteristics of the learning activity.

Cai et al. [3] stated that any definition of classroom-based learning opportunities must necessarily consider the interactions between three elements: the mathematics tasks, the teaching, and the students. They considered it impossible to separate out the influence of any of these components, since the nature of their interactions will determine whether an activity, or a classroom experience, becomes a learning opportunity for a given group of students in relation to a specific goal. Accordingly, Cai et al. [3] stated that the interactions between the three elements create complexities that can probably only be understood by means of multiple iterations of studies based on successive conclusions. In order to make progress, they suggest that multiple studies, often small-scale ones, must be carried out to move gradually towards more complete and accurate answers. Among the research methods they proposed is the study of the mathematical task set for students.

In recent years, a good number of studies of mathematics education related to mathematical learning opportunities have focused on teaching quality and the resources used, analyzing how the pedagogical and/or curricular characteristics of the teaching facilitate or limit students' opportunities to learn. In this respect, the study carried out by Wijaya, van den Heuvel-Panhuizen, and Doorman [42], who concluded that the lack of tasks in context-based textbooks limits students' learning opportunities, is particularly interesting in our opinion. These authors developed a framework with four perspectives for analyzing the role of context in mathematical activities: the types of context, the purpose of context-based tasks, the information used in tasks, and the type of cognition required by the tasks.

Wijaya, van den Heuvel-Panhuizen, and Doorman [42] concluded that when the procedure to be applied is made more or less explicit, students do not need to determine what the appropriate mathematical procedures might be to solve the task, which means they will not develop their ability to transform a context-based task into specific learning. These authors recommended including more tasks based on real-life contexts in classroom practice, and they set out how these tasks should be introduced. First, they pointed out that they should not only appear immediately after the explanations of concepts or procedures, since then the strategies to be followed seem clear. The quality of the tasks is also important: they should be presented in essential, relevant contexts, which can generate opportunities to mathematize situations or organize them mathematically. In addition, the assignments should, according to these authors, incorporate superfluous information or require a search for new information so that students have the opportunity not only to select what is relevant, but also to identify appropriate procedures. They should be tasks with a high cognitive demand so that students have the opportunity to develop complex reasoning, which requires reflection in relation to real-life contexts.

Research has shown that tasks posing a greater cognitive challenge intensify students' involvement in mathematical ideas (Boaler and Staples [43]; Tarr et al. [44]). Tasks with a high cognitive demand require the connection of procedures to their underlying concepts, or the completion of complex, non-algorithmic tasks; tasks with a low cognitive demand involve the memorization or performance of procedures without connecting them to the underlying concept. The best learning opportunities arise when the task meets two conditions. On the one hand, it should require the use of two or more forms of representation (Lesh, Cramer, Doerr, Post, and Zawojewski [45]) and the translation between them, and on the other, it should oblige students to explain their strategies and thinking (Walkowiak, Pinter, and Berry [46]). Ultimately, mathematical tasks play a central role in the type of interactions that are possible and in the nature of the learning opportunities that emerge (Cai et al. [3]).

Our study is among those that analyze factors related to the quality of teaching, and more specifically, the activities proposed to students. Therefore, we analyze the project as an activity that can 
generate learning opportunities, based on the study of what the students show they learned during its development. The study of learning opportunities in conjunction with classroom activities has been based traditionally on three basic methods: direct observation in the classroom, teacher's reports, and documentary analysis of different elements, including the students' products (Kurz [39]). Kurz and Elliott [47] suggested that the learning opportunities generated by an activity can be studied according to what students show they are capable of doing when coping with the activity.

\section{A Case Study Research Design}

Below, we present the case study carried out with the goal of supporting the concept of MMPOSIs as generators of learning opportunities. Whereas this research was a case study (Merriam [5]; Stake [6,7]), the object of study was a bounded system (Stake [8]) where we worked essentially with qualitative data and with the intention of providing a detailed account of the case. Our case was an inclusive one (Cresswell [48]; Merriam [5]; Yin [49]) since we not only focused on an object with a clear entity (a group of people), but we were also interested in studying an activity under development. Case study research can be used to address exploratory, descriptive, and explanatory research questions (Stake $[7,50]$; Merriam [5]; Yin [49]). Our research was an instrumental descriptive case study since it provided initial insights into an issue (Stake [7]). Then again, our interest went beyond understanding the particular case because we hoped that the project Let's get to school safely would illustrate how MMPOSIs operate as generators of learning opportunities.

All case studies have one thing in common: they focus on a case as a complete unit, just as it exists in its real-life context. When determining the case to be studied, we used purposive sampling, taking advantage of the opportunity to participate in the orientation of the project offered by the center. In this case study, we adopted a naturalistic perspective and took the role of research observers during an activity developed naturally at a school (Hatch [51]). We had no control over the environment or the variables that influenced the students' work, but we were able to obtain a close-up view of how things happened in reality.

In research designed as a case study, the researcher must provide a detailed account of the case. We present a detailed comprehensive description of the development of the project Let's get to school safely in the following section, organizing it around what we call episodes. In each of them, the students worked on a core activity based on the four specific goals of the project. The development of the project was documented with photos, videos of specific moments, and notes from classroom observation. We also collected all the work material produced by the sixth graders, which included maps that showed the routes taken by students to get to school, reports of measurements of danger points in the surroundings of the school, guidelines for safe walking, and presentations created to inform other students at the center.

The research issues that focus this study (Stake [8]) and the findings presented in this article revolve essentially around two ideas: the mathematics learning opportunities promoted by the project, and the mathematical models developed by the students during the project. Consequently, various methods of data collection were used: the primary data comprised the field notes together with the documents produced by the students, while the informal interviews with the teacher and the parents provided the secondary data. We drew on these data to develop what was essentially a content analysis that followed the steps proposed by Miles and Huberman [52], consisting of data reduction, data visualization, and conclusion/verification. Specific codes were used to group the data into the emerging categories that became obvious, and the categories were organized into two themes around the research issues.

In this way, we start with a description of the development of the project Let's get to school safely, and then, we analyze it through different levels of abstraction and provide our interpretation of the development of the project, relating it to our conceptual framework, i.e., the learning opportunities and construction of mathematical models. The discussion of the findings and the themes that emerged 
from the categories led to the interpretation of the case studied. We conclude by proposing a detailed characterization of MMPOSIs that goes beyond the initial definition.

\section{Development of the Project in the Classroom}

The project that was the object of our case study was implemented in a school that has one class group per grade and welcomes students from three to eleven years old. As explained in the Introduction, the school is located in the center of a city with a high population density and surrounded by narrow streets shared by cars and pedestrians. Since most students go to and from school on foot, difficulties and potential dangers are generated by the coexistence of cars and pedestrians in a small area. Both the parents' association and the teaching staff had expressed their concern in this respect and proposed various activities to deal with these potential dangers.

Among other activities, the project Let's get to school safely was launched. The older students (sixth grade in elementary education, a group of twenty-six 11-year-olds) would study and analyze the routes to school taken by each of the rest of the students at the school, the goal being to establish appropriate guidelines and recommendations so that the children could get to and from school safely. The project took place over two weeks in six sessions lasting 90 min each. In the first session, the project and its role as a generator of recommendations for the rest of the students at the school were discussed. The teacher and the first author helped the students define the core activities of the project. These were: (i) identify the most common walking routes to the school; (ii) identify potentially dangerous places and situations for students on these routes, (iii) analyze these places to determine safe practices; and (iv) communicate the results of the project to the rest of the school.

Below, we describe how each of the core activities was carried out during the different episodes of project development in order to provide the reader with the details of the case under study.

\subsection{Episode I. Identification of Routes}

Eight work groups were set up in the sixth grade class. Each of these groups focused on studying one of the classes in the lower grades, which was their target class. Students were encouraged to choose a class where they had connections (siblings, neighbors, friends) so as to make communication easier and encourage greater involvement. As a first step, students asked students in their target class about the routes they use to get to school. This step was particularly challenging for the students who worked with the youngest children. Figure 1 shows a sixth grade student asking a four-year-old girl about the route she follows. Given her age, the younger student still had difficulty describing the route she takes to school. For this reason, the sixth grade student asked questions about well-known buildings, squares, and shops that she might recognize on the route in order to obtain the required information. This was then displayed on a map of the school surroundings.

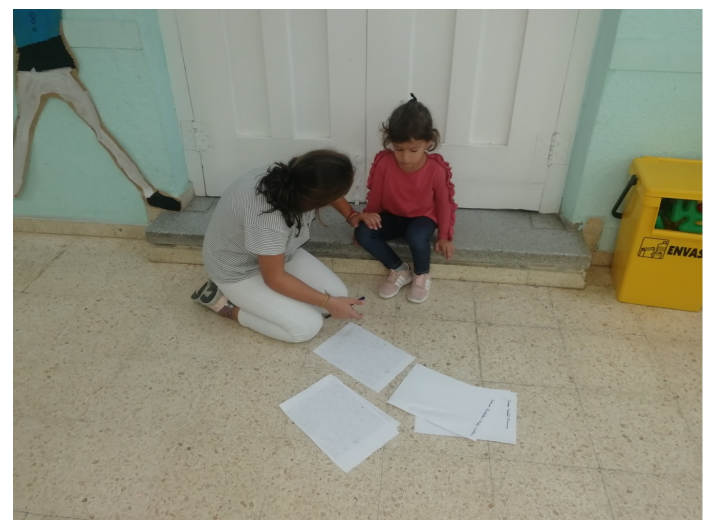

Figure 1. A sixth grade student asking a four-year-old girl about the route she takes to go to school. 
Once all the routes followed by all the students in each target class had been ascertained, the data had to be organized to make decisions. At this point, various interesting findings emerged from the data, such as the distribution of the students' homes or the age at which they begin to learn their route to school in detail. The sixth grade students observed that, below the third grade of primary education (8- to 9-year-olds), there is no guarantee that a child will know the details of the route that he/she usually takes. This prompted other questions that were discarded because they strayed from the main goal of the project. The sixth grade students decided that, for each target class, they would represent the routes followed by the students on a single map in order to structure the subsequent project activities (Figure 2).

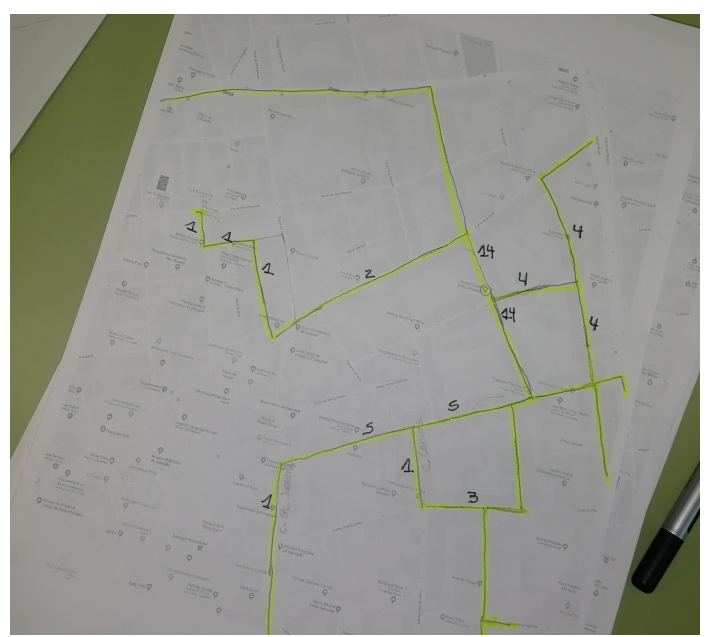

Figure 2. A map showing the routes taken by the students in a target class.

\subsection{Episode II. Identification of Danger Points}

The next phase focused on identifying danger points in the surroundings of the school and examining them to identify the factors that could provoke accidents. To do this, a map of the area around the school was projected onto the classroom screen, and the students discussed the characteristics of the streets and nearby intersections and their own dangerous experiences in these places. When students considered it necessary, they used the Google Maps tool to visualize the streets from an immersive perspective and explore them virtually. The final product of this discussion was a list of danger points requiring further investigation (Figure 3). The danger points were then distributed among the groups for study, bearing in mind in each case that the point had to be part of a route frequented by the target class corresponding to the work group.

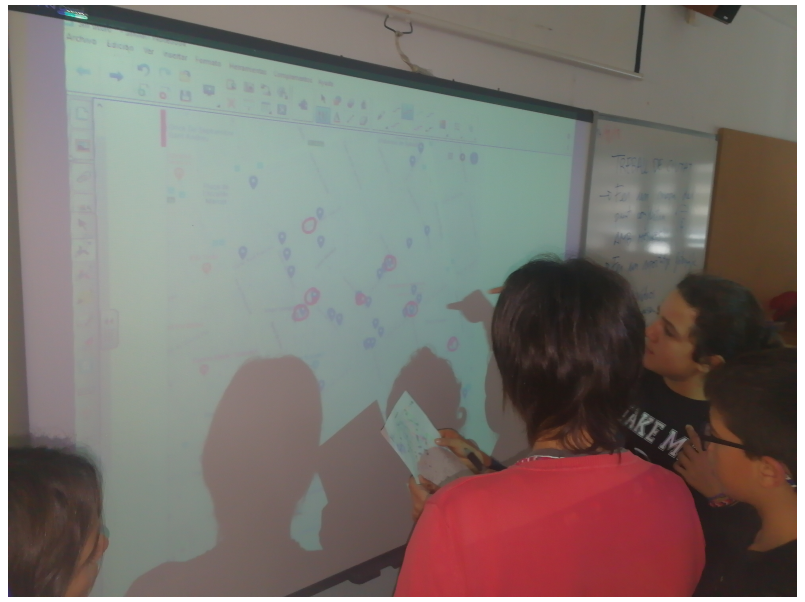

Figure 3. Identifying danger points in the surroundings of the school. 


\subsection{Episode III. Analysis of Danger Points and Preparation of Recommendations}

Episode III consisted of fieldwork. Most of the risk points were street intersections with crosswalks presenting specific characteristics. These characteristics were discussed beforehand in the classroom during Episode II, since upon separating to do the fieldwork in the surroundings of the school, the students were unable to consult the teacher directly. This prior knowledge helped the students to work more efficiently in the field and ensured they obtained the necessary data.

For this activity outside the school, we counted on the assistance of 16 parents from the center who volunteered to make sure the activity went smoothly and looked after the students' safety while they were working in the streets. Each of the groups went to the place to be studied with the intention of drawing up their own map of the area, measuring the relevant features from the standpoint of the passage of vehicles and pedestrians, and indicating the way the latter group moves around. They also took photographs to illustrate their work and recorded videos simulating everyday situations to illustrate the difficulties encountered by pedestrians.

Once they had identified the potential dangers of each one of the points of interest and analyzed the causes, the sixth graders set about identifying safe behaviors that would enable students to move around securely. This search for safe behaviors began in the street and ended later, in the classroom, while the students were preparing to communicate the results of their project.

\subsection{Episode IV. Communication of Project Results}

During this episode, each group shared its proposals with the other class groups in order to reach a consensus. The information obtained was distributed to help each work group prepare the informative talk that they would give their target class. This collaborative approach made it possible to validate each group's proposals and also optimize the impact of their efforts with the preparation of experts on each risk point. The groups adapted the message content to the age of the target students in order to properly communicate the results of the project. Furthermore, thanks to their personal relationships, they were able to exemplify good practices based on specific cases. The presentations began with an introduction that insisted on the right to be able to move safely around the city. After that, each work group explained the procedure followed during the project, the difficulties encountered at the risk points, and their recommendations for safe passage through them. The talks with the different target classes were organized in parallel on a Friday afternoon, and the parents were also invited to learn about the project and its conclusions.

\section{Theme 1: Mathematics Learning Opportunities}

In this and the following section, we report the findings of this study, presenting the two emerging themes through a robust description (Merriam [5]) that incorporates the constructed categories and exemplifies them with units of meaning drawn from the data. This enabled us to show that there were learning opportunities and that models were generated.

The first emerging theme comprised the mathematics learning opportunities that appeared during the development of the Let's get to school safely project. Cobb and Whitenack [4] held that mathematical learning is a process of conceptual self-organization and enculturation. From this perspective, a mathematics learning opportunity is a situation in which students have the chance to reorganize their conceptual structures and approaches when solving problems or, in general, when they have to cope with a new mathematical activity. For each episode in the project, we identified mathematics learning opportunities by analyzing the actions taken by the students-understood as mathematical processes-in response to the proposed activity. These are indicated in italicsbelow.

During Episode I-route identification-the sixth grade students prepared the data collection and established a specific way of recording the information they would collect. The students discussed the various options and selected the most relevant ones. Thus, they realized that writing down the home address of each student in the survey was not relevant since it did not determine the route 
taken. Conversely, they noted that other options, such as recording the information on a printed map, generated useful data that clearly reflected the students' journeys. This discussion represented an opportunity to reflect on the complexity of the phenomenon under study, the nature of the data to be collected, the data collection procedures that they were familiar with, and how they would need to use these data during the subsequent development of the project.

When the sixth grade students asked the students in their target classes about their routes, this led to an interaction that contained various types of mathematical content. In all cases, the first step was for the sixth graders to explain the information on the map and present the way to interpret it, working on orientation on a map and obliging the younger students to identify specific landmarks in the city (parks, buildings, and shops) with points on the map, and relating the directions of movements on real routes with movements on the map. The younger students had to visualize their daily route to school and adapt their explanations to the needs of the sixth graders. This process of visualization included interpreting graphic information on the map and the visual processing of the route they use to go to school, with these two procedures understood as in Bishop [53] and Gorgorió [54].

Once the sixth grade students had identified all the routes, the mathematical activity focused on understanding the information they had collected. To do this, the students were asked to organize the maps and then classify the identified routes into sets, where the routes had to have a large section in common. We observed that the students hesitated when grouping routes with slight variations. The need to reduce the complexity of the situation was discussed in order to be able to study it with the methods at hand. After creating the sets of routes, each group had to draw up a map showing the frequency of use of all the streets around the school (Figure 4). This process of representing information included visual coding, since students developed their own graph format. Previously, they had only worked with pie charts and bar graphs in statistics as resources to represent frequency.

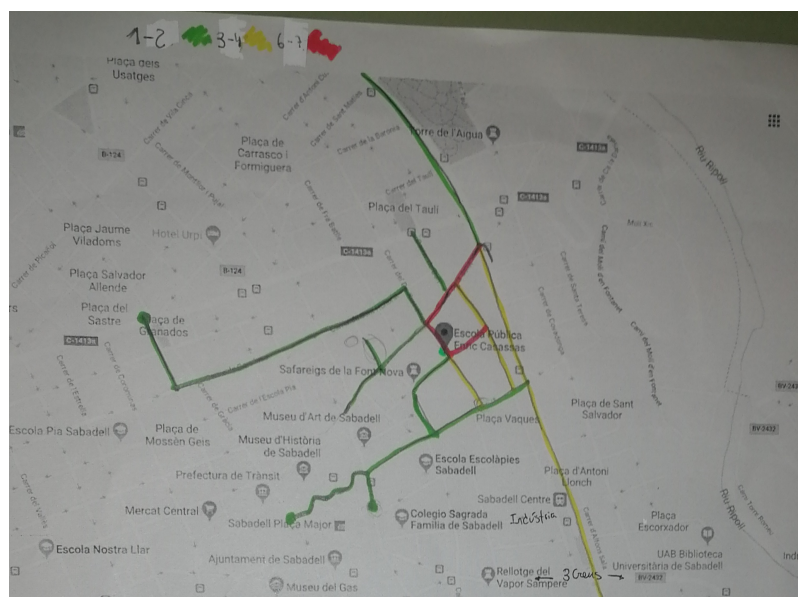

Figure 4. A map showing the intensity of use of the different routes taken to go to school.

In Episode II-danger points-the first mathematical activity consisted of drawing up a proposal for a list of dangerous places for pedestrians in the surroundings of the school. The sixth graders were asked to identify them on their own journeys to and from school and to try to visualize possible risk situations for younger students. This obliged the sixth grade students to reinterpret the use of the streets from the perspective of people with more limited mobility and who see the world from a lower height. This activity involved a visual processing procedure because it required anticipating movements and lines of sight that would be verified and complemented in the later field study. Before accepting a proposed risk point, students were required to verbally describe a potentially dangerous situation that could occur in that spot. This activity demanded spatial reasoning, since students had to describe the movement of different objects (vehicles and people) and their form of interaction. The various validated risk points were situated on a map, thereby repeating the activity of location on the map. 
In Episode III-analysis of danger points and generation of recommendations-various mathematical activities related to the use of measurement in context and the representation of reality on a map were carried out, both as regards urban architecture and the use of the street by vehicles and pedestrians. Students recreated possible risk situations and took various types of measurement that were relevant to understanding how cars could interact negatively with pedestrians. They recorded them on a map of the risk point under study.

The corner in Figure 5 is shown by way of an example. As you can see in the picture, the curb has been lowered to allow cars to turn more easily. The students measured by how much the cars mount the sidewalk.

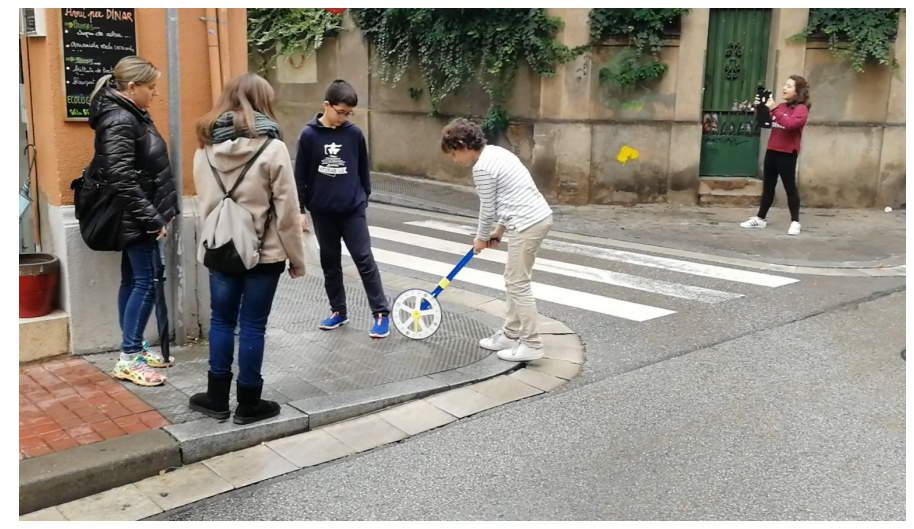

Figure 5. Fieldwork measuring the width of the sidewalk mounted by cars when turning.

In other cases, students measured how high a pedestrian needs to be for a driver to see him/her when waiting at a zebra crosswalk where the adjacent parked cars limit the drivers' field of view. Students also measured the angle necessary for a pedestrian at that same crosswalk to see a car approaching and have enough time to stop. In all these cases, the measurements they took were not of objects in the street, but rather measurements of distances that the students determined by visualizing the interactions between vehicles and pedestrians, because they offered information relevant to the decision-making in the following part of the project.

Lastly, in Episode IV_communication of the project results—-the mathematical activity consisted of the interpretation of the collected data to prepare guidelines and recommendations for the students in the other grades. They used videos, photographs, screenshots of Google Maps, and annotations with measurements to distinguish safe behaviors from risky ones. This implied using this information in a contextualized manner, interpreting the mathematical model generated in relation to the real world; they had to consider traffic regulations and also the usual behavior of vehicles and pedestrians.

Figure 6 shows the categories that summarize the mathematics learning opportunities identified during the development of the project. 


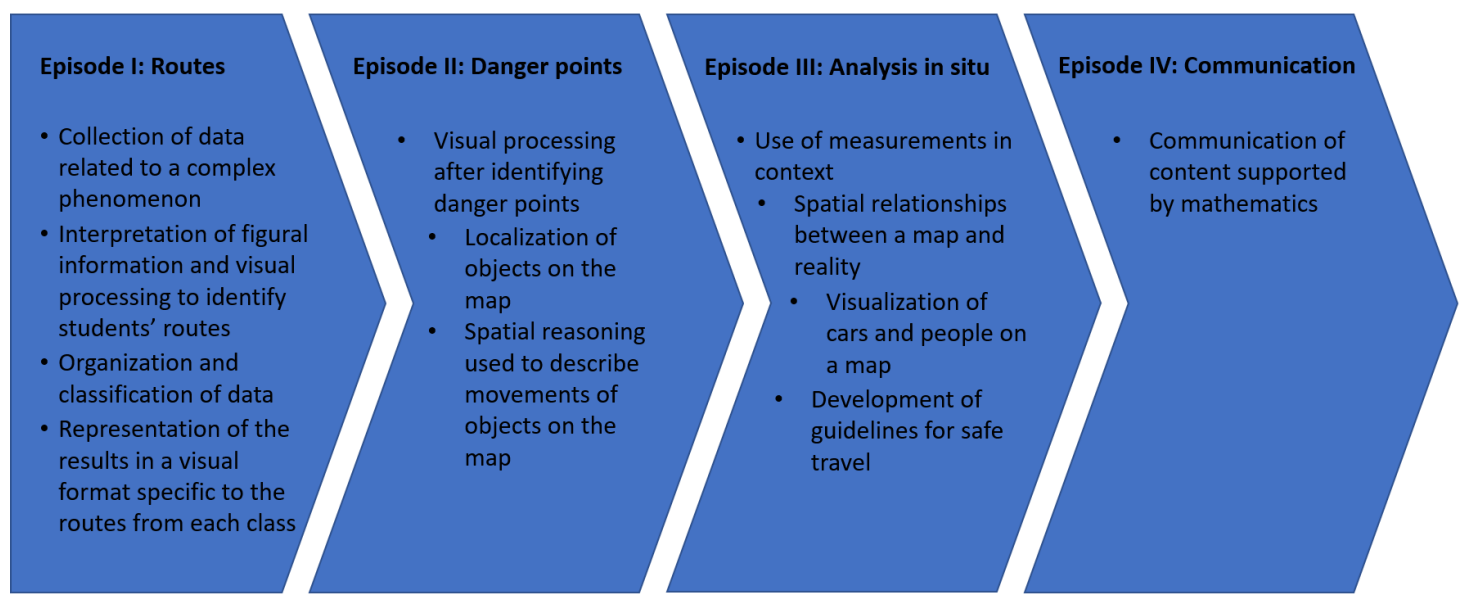

Figure 6. Mathematical learning opportunities identified during the project.

\section{Theme 2: Models Generated}

The second emerging theme consisted of the mathematical models created by the sixth graders during the development of the Let's get to school safely project. Mathematical models are conceptual systems that describe real phenomena (Lesh and Harel [26]), but from the research standpoint, the identification of the conceptual systems generated by students turns out to be rather complex. However, models are implemented according to specific procedures associated with these concepts. In previous works, we developed a tool for the characterization of mathematical models (Albarracín [55]; Albarracín and Gorgorió [56]; Gallart, Ferrando, García-Raffi, Albarracín, and Gorgorió [57]), which was based on identifying the chains of procedures that students implement and how these procedures are represented. In this study, we observed that sixth grade students created two types of mathematical models to tackle two aspects that were crucial to the development of the project: (i) maps of route use intensity and (ii) safe travel recommendations for other students.

\subsection{Maps of Route Use Intensity}

The first mathematical model they created consisted of the maps of route use intensity in the streets around the school. These maps were obtained from the data collected from the other students at the school, and they describe the phenomenon of student travel to school. The generation of these maps was crucial to the project because they were what enabled the students to identify the risk points to be studied. Table 1 describes the mathematical procedures that shaped the model.

Table 1. Description of the modeling process used to generate a map of route use intensity in terms of identified procedures.

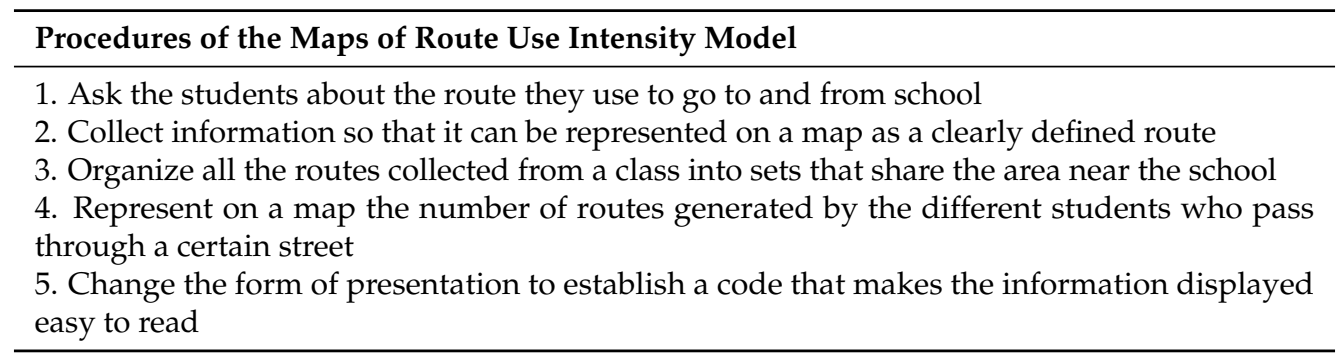

A sample of the work involved in making these maps of route use intensity is shown in Figure 7. On the left, Figure 7a shows two students grouping the maps with the individual routes to make the map of route use intensity. On the right side, Figure $7 \mathrm{~b}$ shows two different steps in the preparation of the same map. On the left, a count of the number of students passing through each street is shown. 
On the right, the finished map is shown, with the numerical information simplified into a color code with the busiest streets marked in red.

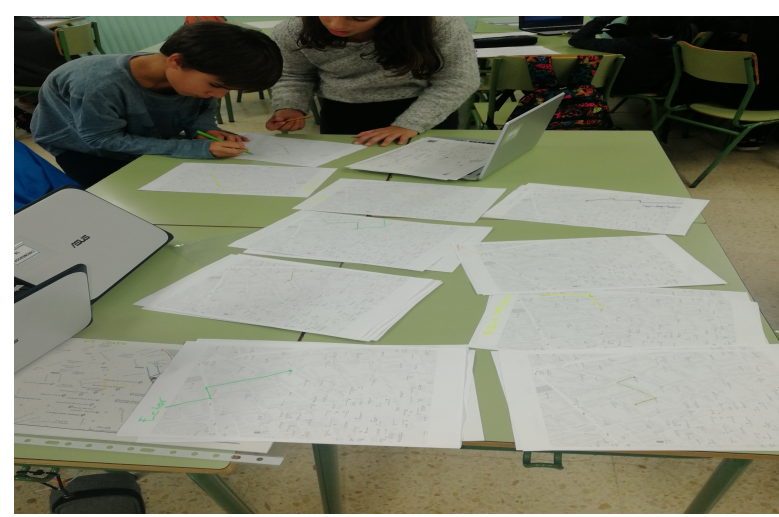

(a)

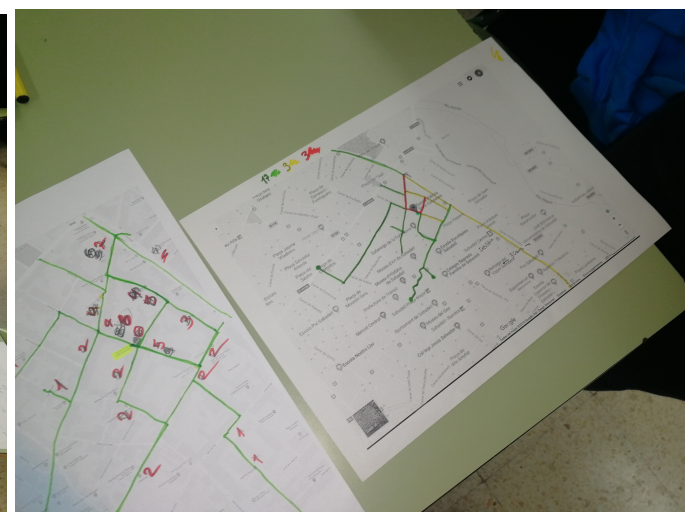

(b)

Figure 7. (a) Organizing the collected routes, (b) representing them on a single map.

From the perspective of M\&M, these maps are clearly the result of modeling work. They display the use of the streets for going to school and are a product that supported subsequent decision-making on how to prioritize the risk points that students were going to study. The sixth grade students used these maps as a starting point to establish a criterion of selection based on determining those risk points most frequented by students in the target classes.

\subsection{Recommendations for Safe Travel}

The second type of mathematical model generated was the set of recommendations for safe travel in the streets. These recommendations emerged from the analysis of the layout of the areas under study and the way cars and pedestrians move through them, and from the predictions made about what they considered safe behavior. Table 2 describes the mathematical procedures that shaped the model.

Table 2. Description of the modeling process used to generate recommendations for safe travel in terms of identified procedures.

\begin{tabular}{l}
\hline Procedures of the Recommendations for Safe Travel Model \\
\hline 1. Imagine and simulate the movement of vehicles and pedestrians on the street \\
2. Identify possible interactions that put pedestrians at risk \\
3. Represent the interactions of risk on a map, and take the measurements (distances and \\
angles) that characterize them \\
4. Propose alternatives for pedestrian movement to avoid risk situations \\
5. Represent recommendations for safe action on a map, using indicators of movement
\end{tabular}

Given the diversity of black spots in the area around the school, we show two examples of the recommendations drawn up by the students in their work. In the first example, the students decided that the corner shown in Figure 8 represents a potential risk area for pedestrians heading towards it from the north. Therefore, they indicated this movement with a red arrow in Figure 8 . This becomes a danger point if a car mounts the sidewalk at the same time as when a pedestrian coming in the opposite direction turns the corner, since the two paths cross. The students suggested that pedestrians should avoid that corner by using two crosswalks, i.e., following the green arrow. This movement is not really natural as it forces pedestrians to walk a greater distance than the red option, but the field of view of both pedestrians and drivers is better at each crossing. 


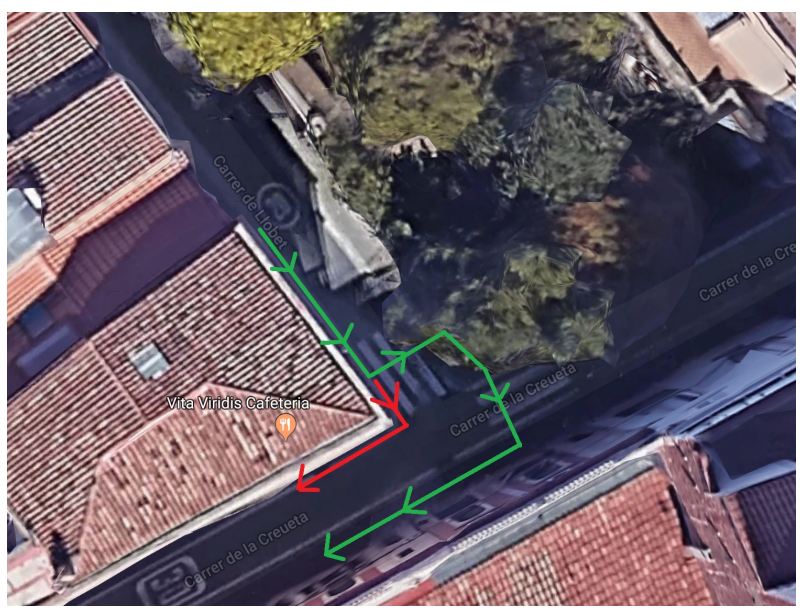

Figure 8. Scheme with recommendations for use at a corner where cars may mount the sidewalk.

The second example concerns a T-intersection where cars that turn right have to give way to cars coming from their left (Figure 9a). There is a mirror at the intersection so that drivers can see whether it is safe to turn without having to pull halfway out into the other street (Figure 9b). The need to pay attention to the left means that drivers do not pay much attention to the right when turning. As in the previous case, a car could easily mount the sidewalk on the right-hand corner and hit someone walking there. For this reason, the students in their recommendations suggested walking on the left-hand sidewalk (Figure 9c), marking it in green on the map, so that they would always be in the drivers' field of view and be able to use the crosswalks when the vehicles stop.

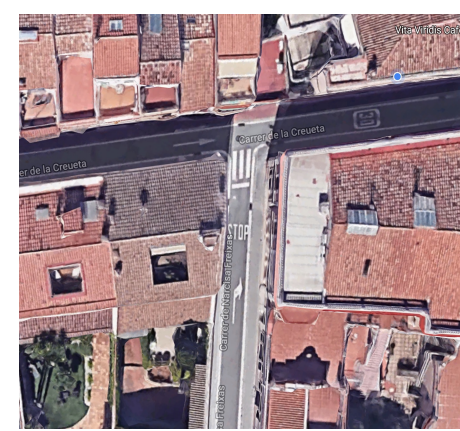

(a)

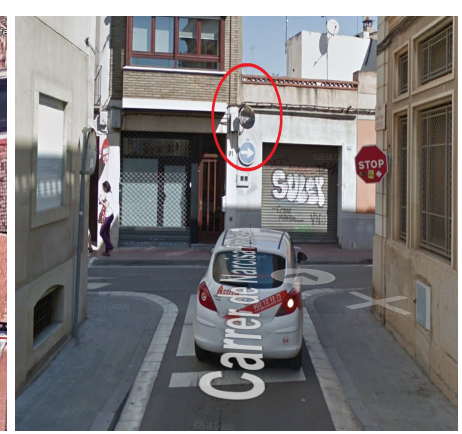

(b)

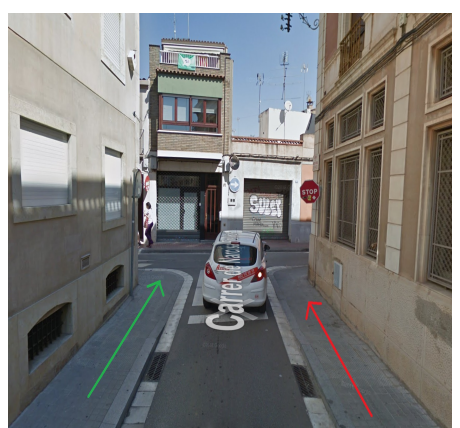

(c)

Figure 9. (a) Aerial view of the corner under study; (b) drivers' focus of attention; (c) recommendations for use represented by arrows.

The students' set of recommendations was the product of a modeling process that enabled us to distinguish between good and bad practices when moving through the streets. The recommendations were specific to each situation studied, but the procedure for creating them is shareable and reusable in other analogous situations. Beyond this possibility of direct transfer, the generated model could be used for the design of safe behaviors for other users in other situations, such as drivers of cars and other vehicles. Moreover, the sixth grade students communicated the recommendations resulting from their study to the rest of the students, highlighting that their construction was based on mathematical arguments and procedures. In this way, mathematics constituted a validating component of the work carried out.

\section{Discussion}

The results of this case study showed that the Let's get to school safely project generated a large number of mathematical learning opportunities for the sixth graders. During the project, students had 
to cope with activities that required the coordinated use of different content and mathematical skills. Statistical data collection, information processing, data coding, visualization, mapping, and measurements, among other processes, were highly relevant to shaping the mathematical models. Each of the work groups was responsible for studying the routes of one of the school classes and for providing age-appropriate recommendations for these students.

During Episodes I and II, the work groups focused on collecting and organizing the data obtained from their target classes, thereby raising opportunities for mathematics learning that had to be consolidated by means of concrete products in order to continue the project. During Episode III, each of the groups was responsible for analyzing a risk point and preparing specific recommendations for safe passage through that point. The sense of responsibility developed during the project was what compelled the various work groups to address the learning opportunities that emerged during the project and transform them into concrete learning that manifested itself in the form of tangible products. In other words, the responsibility of each group in the project was the medium that promoted the construction and reconstruction of mathematical models, which is the main objective of modeling activities that take the M\&M approach (Doerr and English [2]; Lesh, Amit, and Schorr [35]; Mousoulides, Sriraman, and Christou [34]).

Some of the ideas and proposals examined to generate the different models that supported the products of the project began with interaction among a small number of students, who were the ones who contributed the ideas in the first place. However, following group discussions involving the entire class, each of the work groups had to consider, interpret, and implement these ideas according to their own needs. Thus, the project encouraged the students to explain their strategies and reasoning (Walkowiak, Pinter, and Berry [46]) relative to the mathematical activities for which the students had decided what information they needed and the methods needed to analyze it (Wijaya, van den Heuvel-Panhuizen, and Doorman [42]). We concur with Törnroos [40] when he stated that the existence of learning opportunities does not imply that learning is consolidated. However, during the project, we saw how the students developed a form of collaboration where the mathematical contents and methods constituted the core of the activity. Therefore, what we observed leads us to think that the students learned to work mathematically as a team. Not only that, they also developed a sense of belonging to the school community.

The project had an impact on other school groups apart from the sixth grade students. The younger students saw how their schoolmates in the last year were interested in a problematic aspect of their daily lives. The sixth grade students asked them about their experiences and later gave them explanations - tailored to their level of comprehension and their practical needs_about factors that they had to take into account to guarantee their own safety when walking the streets. The explanations about the analysis and decision-making process that the sixth graders gave the younger students were an essential aspect of this informative procedure. Thus, mathematics played a clear role as a validator of the project results for the rest of the students. Besides that, some of the children's parents were able to participate actively in one of the activities, and others attended the final informative talks. In all cases, their children received information that made it possible to address safe behavior on the streets from within the family unit, taking the results of the project as a starting point.

From the point of view of the teaching staff, the project brought to light a new way of teaching students to use mathematics in context. Furthermore, the project format, based on the analysis of a social reality in order to generate safe behavior guidelines, provides a guide for teachers. This format could allow them to overcome some of the difficulties identified in the literature, because when students contribute a variety of ideas that are difficult to manage ( $\mathrm{Ng}$ [19]; Winter and Venkat [20]), the teacher can refer directly to the needs of each episode of the project to decide if the students' proposals point in the right direction and prioritize them appropriately. We understand that teachers must have an active mathematics disposition if they are to adequately guide their students. In other words, they must be open to asking themselves questions and setting themselves problems, have a knowledge of specific cases where mathematics helps to understand real situations, and be able 
and willing to document themselves or seek specific help when they are not acquainted with the mathematics necessary to interpret or describe a situation. It is also necessary that teachers be trained to work in the classroom using open projects or have the experience needed to do so, even if they are not strictly mathematical projects. Thus, a key aspect of the role played by teachers is to identify the mathematical contents that students generate in order to properly organize and institutionalize them.

\section{Conclusions}

The case study developed around the project Let's get to school safely permits the characterization of a new type of school project that we labeled mathematical modeling projects oriented towards social impact and informs us of its possibilities, showing us that such projects can be generators of learning opportunities, as explained above. We conclude this article with a description of the basic characteristics of MMPOSIs.

First of all, a modeling project geared towards social impact must tackle the needs of people as a community (for example, road safety, pollution, immigration, etc.) and must be structured with the intention of having a direct impact on the educational community, either on the students themselves, their families, or other close groups of people with similar needs. In this way, the issue tackled in the project arises from the students themselves or the school itself, and the product resulting from the modeling process has a real impact on the community, even beyond the group of students who develop it. Furthermore, it is the fact of developing a sense of responsibility towards the community that leads to the search for solutions, thus favoring the emergence of mathematics learning opportunities and, in particular, stimulating students to take advantage of them. We call this characteristic the principle of social impact.

Then again, for an intervention to be an MMPOSI, it must be structured in such a way that it demands an analysis of the phenomenon from the perspective of mathematical modeling. It should be possible to organize the project into various coordinated activities that act as MEAs (Doerr and English [2]), which encourage the students to generate products based on a mathematical model, which can be communicated to and used by the project target group. Thus, the development of this type of project obliges the students to decide what information is needed to tackle it and what methods are required to analyze it, as well as to explain their strategies, procedures, and reasoning to their peers. We call this second characteristic the principle of mathematical modeling.

The mathematical knowledge gained during the project should support actions that provide a return to the educational community. Mathematical knowledge provides a basis for student decision-making and, at the same time, plays a key role in validating the results of a project when it is presented to other students. We call this third characteristic the principle of mathematical justification. In MMPOSI, mathematical modeling plays a twofold role. On the one hand, it allows students to develop their mathematical competence in complex situations that are familiar and relevant to them, and on the other, mathematics serves as a tool for validating the results. This mathematical validation also offers students a way to defend their products, since it is a procedure that guarantees the suitability of their recommendations for solving the problems under study. In previous studies, we observed that when students produce their own mathematical explanations of social phenomena, they tend to trust their own methods and conclusions to such a point that they generate a framework to support their decisions and freely criticize the results provided by external sources, such as information that appears in the media (Albarracín and Gorgorió [58]).

Producing safe proposals to move around the city demands complex, relevant decision-making, which entails developing a high level of responsibility and social awareness. The process leads students to question the way in which their environment is constructed, and given the doubts raised, they come up with their own ideas about how a city should be organized. Thus, group work, the connection of mathematical knowledge with reality, and the use of different technologies to collect, organize, and interpret data come together so that students can take a reasoned position on relevant social aspects that affect them. This requires the coordination of knowledge and procedures typical of different 
disciplines, with which MMPOSIs can provide a way of promoting interdisciplinary work without reducing the role of mathematics to a minimum expression. They thereby play an active role as members of the community who begin to make their own decisions and develop their own ideas of what the world they live in should be like.

Finally, we would like to make it clear that because this case study was instrumental, i.e., developed with the intention of illustrating a concept, its findings should not be regarded as all-inclusive or generalizable. Given that we started from naturalistic observation to exemplify and characterize a new theoretical construct, it is obvious that this study needs to be followed up by others to continue exploring MMPOSIs at different educational levels and with different teachers, both in terms of their mathematical knowledge and their approach to mathematics. In particular, we think that it would be interesting to explore how the students' social commitment and sense of belonging to the community impact the emergence of learning opportunities during MMPOSIs and makes these learning opportunities materialize in concrete learning throughout the development of a project of this type. In this research, we saw that the students' survey of the routes led to the study of movements on a map. In this respect, we also think it would be interesting to explore how certain topics could be connected to develop projects with specific mathematical content. For this reason, we think that it would be worth studying teachers' modeling competencies, to see in particular if they can identify a priori these connections between reality and mathematical content.

Author Contributions: Conceptualization, L.A. and N.G.; methodology, L.A. and N.G.; formal analysis, L.A. and N.G.; investigation, L.A.; resources, L.A.; data curation, L.A. and N.G.; writing, original draft preparation, L.A. and N.G.; writing, review and editing, L.A. and N.G.; supervision, L.A. and N.G. All authors read and agreed to the published version of the manuscript.

Funding: This research was funded by Ministerio de Economía, Industria y Competitividad (Spain) Grant Number EDU2017-82427-R and Agència de Gestió d'Ajuts Universitaris i de Recerca (Generalitat de Catalunya) Grant Number 2017 SGR 497. The work of Lluís Albarracín is supported by Serra-Húnter program.

Acknowledgments: In loving memory of Roger Canudas Torralba.

Conflicts of Interest: The authors declare no conflict of interest.

\section{References}

1. Blum, W. ICMI Study 14: Applications and modeling in mathematics education-Discussion document. Educ. Stud. Math. 2002, 51, 149-171. [CrossRef]

2. Doerr, H.M.; English, L.D. A modeling perspective on students' mathematical reasoning about data. J. Res. Math. Educ. 2003, 34, 110-136. [CrossRef]

3. Cai, J.; Morris, A.; Hohensee, C.; Hwang, S.; Robinson, V.; Cirillo, M.; Kramer, S.L.; Hiebert, J.; Bakker, A. Maximizing the Quality of Learning Opportunities for Every Student. J. Res. Math. Educ. 2020, 51, 12-25. [CrossRef]

4. Cobb, P.; Whitenack, J.W. A method for conducting longitudinal analyses of classroom videorecordings and transcripts. Educ. Stud. Math. 1996, 30, 213-228. [CrossRef]

5. Merriam, S.B. Case Study Research in Education: A Qualitative Approach; Jossey-Bass: San Francisco, CA, USA, 1998; 248p.

6. Stake, R.E. The case study method in social enquiry. Educ. Res. 1978, 7, 5-9. [CrossRef]

7. Stake, R.E. The Art of Case Study Research; Sage Publications: Thousand Oaks, CA, USA, 1995; 177p.

8. Stake, R.E. Case Study Methods in Educational Research Seeking Sweet Water. In Complementary Methods for Research in Education; Jaeger, R.M., Ed.; American Educational Research Association: Washington, DC, USA, 1997; pp. 253-300.

9. Pollak, H. How can we teach application of mathematics? Educ. Stud. Math. 1969, 2, 393-404. [CrossRef]

10. Pollak, H.O. The interaction between mathematics and other school subjects. In New Trends in Mathematics Teaching; UNESCO: Paris, France, 1979; Volume IV, pp. 232-248.

11. Abassian, A.; Safi, F.; Bush, S.; Bostic, J. Five different perspectives on mathematical modeling in mathematics education. Investig. Math. Learn. 2020, 12, 53-65. [CrossRef] 
12. Blomhøj, M. Different perspectives in research on the teaching and learning mathematical modeling. In Mathematical Applications and Modelling in the Teaching and Learning of Mathematics: Proceedings from Topic Study Group 21 at the 11th International Congress on Mathematical Education in Monterrey; Blomhøj, M., Carreira, S., Eds.; Roskilde Universitet: Roskilde, Denmark, 2009; pp. 1-17.

13. Kaiser, G.; Sriraman, B. A global survey of international perspectives on modeling in mathematics education. ZDM 2006, 38, 302-310. [CrossRef]

14. Vorhölter, K.; Kaiser, G.; Borromeo Ferri, R. Modeling in mathematics classroom instruction: An innovative approach for transforming mathematics education. In Transforming Mathematics Instruction; Li, Y., Silver, E.A., Li, S., Eds.; Springer: Dordrecht, The Netherlands, 2014; pp. 21-36.

15. Blum, W. Quality teaching of mathematical modeling: What do we know, what can we do? In Proceedings of the 12th International Congress on Mathematical Education; Cho, S.J., Ed.; Springer: New York, NY, USA, 2015; pp. 73-96.

16. Barquero, B.; Bosch, M.; Romo, A. Mathematical modeling in teacher education: Dealing with institutional constraints. ZDM 2018, 50, 31-43. [CrossRef]

17. Blum, W.; Leiß, D. How do students and teachers deal with modeling problems? In Mathematical Modeling (ICTMA12): Education, Engineering and Economics; Haines, C., Galbraith, P., Blum, W., Khan, S., Eds.; Horwood Publishing: Chichester, UK, 2006; pp. 222-231.

18. Schmidt, B. Modeling in the classroom: Obstacles from the teacher's perspective. In Trends in Teaching and Learning of Mathematical Modeling; Blum, W., Stillman, G.A., Eds.; Springer: Dordrecht, The Netherlands, 2011; pp. 641-651.

19. $\mathrm{Ng}$, K.E.D. Initial perspectives of teacher professional development on mathematical modeling in Singapore: A framework for facilitation. In Teaching Mathematical Modeling: Connecting to Research and Practice. International Perspectives on the Teaching and Learning of Mathematical Modeling; Stillman, G.A., Kaiser, G., Blum, W., Brown, J., Eds.; Springer: New York, NY, USA, 2013; pp. 427-436.

20. Winter, M.; Venkat, H. Pre-service teacher learning for mathematical modeling. In Teaching Mathematical Modeling: Connecting to Research and Practice. International Perspectives on the Teaching and Learning of Mathematical Modeling; Stillman, G.A., Kaiser, G., Blum, W., Brown, J., Eds.; Springer: New York, NY, USa, 2013; pp. 395-404.

21. Lester, F.K. Musings about mathematical problem-solving research: 1970-1994. J. Res. Math. Educ. 1994, 25, 660-675. [CrossRef]

22. Schoenfeld, A.H. Problem solving in the United States, 1970-2008: Research and theory, practice and politics. ZDM 2007, 39, 537-551. [CrossRef]

23. Verschaffel, L. Realistic mathematical modeling and problem solving in the upper elementary school: Analysis and improvement. In Teaching and Learning Thinking Skills. Contexts of Learning; Csapo, B., Hamers, J.H.M., Van Luit, J.E.H., Eds.; Swets \& Zeitlinger: Lisse, The Netherlands, 1999; pp. 215-240.

24. Krajcik, J.S.; Blumenfeld, P. Project-based learning. In The Cambridge Handbook of the Learning Sciences; Sawyer, R.K., Ed.; Cambridge University Press: New York, NY, USA, 2005; pp. 317-334.

25. Blumenfeld, P.; Soloway, E.; Marx, R.W.; Krajcik, J.S.; Guzdial, M.; Palincsar, A. Motivating project-based learning: Sustaining the doing, supporting the learning. Educ. Psychol. 1991, 26, 369-398. [CrossRef]

26. Lesh, R.; Harel, G. Problem solving, modeling, and local conceptual development. Math. Think. Learn. 2003, 5, 157-189. [CrossRef]

27. Blum, W.; Niss, M. Applied Mathematical Problem Solving, Modeling, Applications, and Links to other Subjects-State, Trends and Issues in Mathematics Instruction. Educ. Stud. Math. 1991, 22, 37-68. [CrossRef]

28. Carreira, S.; Amado, N.; Lecoq, F. Mathematical Modeling of Daily Life in Adult Education: Focusing on the Notion of knowledge. In Trends in Teaching and Learning of Mathematical Modeling; Kaiser, G., Blum, W., Borromeo Ferri, R., Stillman, G., Eds.; Springer: New York, NY, USA, 2011; pp. 199-210.

29. Galbraith, P.; Stillman, G. A framework for identifying student blockages during transitions in the modeling process. ZDM 2006, 38, 143-162. [CrossRef]

30. Greefrath, G. Using Technologies: New Possibilities of Teaching and learning Modeling-Overview. In Trends in Teaching and Learning of Mathematical Modeling; Kaiser, G., Blum, W., Borromeo Ferri, R., Stillman, G., Eds.; Springer: New York, NY, USA, 2011; pp. 301-304. 
31. Kaiser, G.; Stender, P. Complex modeling problem in cooperative learning environments self-directed. In Teaching Mathematical Modeling: Connecting to Research and Practice. International Perspectives on the Teaching and Learning of Mathematical Modeling; Stillman, G.A., Kaiser, G., Blum, W., Brown, J., Eds.; Springer: New York, NY, USA, 2013; pp. 277-294.

32. Blum, W.; Borromeo Ferri, R.B. Mathematical modeling: Can it be taught and learnt? J. Math. Modeling Appl. 2009, 1, 45-58.

33. Maaß, K. What are modeling competencies? ZDM 2006, 38, 113-142. [CrossRef]

34. Mousoulides, N.; Sriraman, B.; Christou, C. From problem solving to modeling: The emergence of models and modeling perspectives. Nord. Stud. Math. Educ. 2007, 12, $23-47$.

35. Lesh, R.; Amit, M.; Schorr, R.Y. Using Real-Life Problems to Prompt Students to Construct Conceptual Models for Statistical Reasoning. In The Assessment Challenge in Statistics Education; Gal, I., Garfield, J.B., Eds.; IOS Press: Amsterdam, The Netherlands, 1997; pp. 65-83.

36. Clohessy, E.; Johnson, P. Examining the role of group work as an effective instructional strategy when teaching problem solving. In Proceedings of the Tenth Congress of the European Society for Research in Mathematics Education; Dooley, T., Gueudet, G., Eds.; DCU Institute of Education \& ERME: Dublin, Ireland, 2017; pp. 924-931.

37. Zawojewski, J.; Lesh, R.; English, L.D. A models and modeling perspective on the role of small group learning activities. In Beyond Constructivism: Models and Modeling Perspectives on Mathematics Teaching, Learning, and Problem Solving; Lesh, R., Doerr, H.M., Eds.; Lawrence Erlbaum Associates, Inc.: Mahwah, NJ, USA, 2003; pp. 337-358.

38. Lesh, R.; Lehrer, R. Models and modeling perspectives on the development of students and teachers. Math. Think. Learn. 2003, 5, 109-129. [CrossRef]

39. Kurz, A. Access to What Should Be Taught and Will Be Tested: Students' Opportunity to Learn the Intended Curriculum. In Handbook of Accessible Achievement Tests for All Students; Elliott, S., Kettler, R., Beddow, P., Kurz, A., Eds.; Springer: New York, NY, USA, 2011; pp. 99-129.

40. Törnroos, J. Mathematics textbooks, opportunity to learn and student achievement. Stud. Educ. Eval. 2005, 31, 315-327. [CrossRef]

41. Floden, R.E. The measurement of opportunity to learn. In Methodological Advances in Cross-National Surveys of Educational Achievement; Porter, A.C., Gamoraxt, A., Eds.; National Academy Press: Washington, DC, USA, 2002; pp. 231-266.

42. Wijaya, A.; van den Heuvel-Panhuizen, M.; Doorman, M. Opportunity-to-learn context-based tasks provided by mathematics textbooks. Educ. Stud. Math. 2015, 89, 41-65. [CrossRef]

43. Boaler, J.; Staples, M. Creating mathematical futures through an equitable teaching approach: The case of railside school. Teach. Coll. Rec. 2008, 110, 608-645.

44. Tarr, J.E.; Reys, R.E.; Reys, B.J.; Chávez, Ó.; Shih, J.; Osterlind, S.J. The impact of middle-grades mathematics curricula and the classroom learning environment on student achievement. J. Res. Math. Educ. 2008, 39, 247-280.

45. Lesh, R.A.; Cramer, K.; Doerr, H.; Post, T.; Zawojewski, J. Model development sequences. In Beyond Constructivism: A Models and Modeling Perspective on Mathematics Teaching, Learning, and Problem Solving; Lesh, R.A., Doerr, H., Eds.; Lawrence Erlbaum: Mahwah, NJ, USA, 2003; pp. 35-58.

46. Walkowiak, T.A.; Pinter, H.H.; Berry, R.Q. A reconceptualized framework for 'opportunity to learn' in school mathematics. J. Math. Educ. Teach. Coll. 2017, 8, 7-18.

47. Kurz, A.; Elliott, S.N. Overcoming barriers to access for students with disabilities: Testing accommodations and beyond. In Assessing Students in the Margins: Challenges, Strategies, and Techniques; Russell, M., Ed.; Information Age Publishing: Charlotte, NC, USA, 2011; pp. 31-58.

48. Creswell, J.W. Qualitative Inquiry and Research Design. Choosing among Five Traditions; Sage Publications: Thousand Oaks, CA, USA, 1998; 488p.

49. Yin, R.K. Case Study Research: Design and Methods; Sage Publications: Newbury Park, CA, USA, 1994; 282p.

50. Stake, R.E. Case Studies. In Handbook of Qualitative Research; Denzin, N.K., Lincoln, Y.S., Eds.; Sage Publications: Thousand Oaks, CA, USA, 1994; pp. 236-247.

51. Hatch, J.A. Naturalistic Methods in Educational Research. In Annual Meeting of the Centro Interdisciplinario de Investigación y Docencia en Educacion Técnica; CIIDDET: Queretaro, Mexico, 1985; pp. 1-26.

52. Miles, M.B.; Huberman, A.M. Qualitative Data Analysis; Sage Publications: Thousand Oaks, CA, USA, 1994; 354p. 
53. Bishop, A.J. Space and Geometry. In Acquisition of Mathematics Concepts and Processes; Lesh, R., Landau, M., Eds.; Academic Press: Orlando, FL, USA, 1983; pp. 175-203.

54. Gorgorió, N. Exploring the Functionality of Visual and Non-Visual Strategies in Solving Rotation Problems. Educ. Stud. Math. 1998, 35, 207-231. [CrossRef]

55. Albarracín, L. Large Number Estimation as a Vehicle to Promote Mathematical Modeling. Early Child. Educ. J. 2020. [CrossRef]

56. Albarracín, L. Using Large Number Estimation Problems in Primary Education Classrooms to Introduce Mathematical Modelling. Int. J. Innov. Sci. Math. Educ. 2019, 27, 45-57.

57. Gallart, C.; Ferrando, I.; García-Raffi, L.M.; Albarracín, L.; Gorgorió, N. Design and implementation of a tool for analysing student products when they solve Fermi problems. In Mathematical Modeling and Applications. Crossing and Researching Boundaries in Mathematics Education; Eilerts, G.A., Blum, W., Kaiser, G., Eds.; Springer: Cham, Switzerland, 2017; pp. 265-275.

58. Albarracín, L.; Gorgorió, N. On the Role of Inconceivable Magnitude Estimation Problems to Improve Critical Thinking. In Educational Paths to Mathematics; Gellert, U., Giménez, J., Hahn, C., Kafoussi, S., Eds.; Springer: Dordrecht, The Netherlands, 2015; pp. 263-277.

Publisher's Note: MDPI stays neutral with regard to jurisdictional claims in published maps and institutional affiliations.

(C) 2020 by the authors. Licensee MDPI, Basel, Switzerland. This article is an open access article distributed under the terms and conditions of the Creative Commons Attribution (CC BY) license (http://creativecommons.org/licenses/by/4.0/). 